\title{
Thermal Sensitivity Evaluation of Recessed, Flush and Concealed Sprinklers
}

\author{
ROBERT G. BILL, JR. and GUNNAR HESKESTAD \\ Factory Mutual Research Corporation \\ 1151 Boston-Providence Turnpike \\ Norwood, MA 02062 USA
}

\begin{abstract}
Research was conducted to develop plunge test procedures to evaluate the thermal sensitivity of recessed, flush and concealed (RF\&C) sprinklers. Such sprinklers cannot be assumed to be covered directly by the RTI concept, primarily developed for sprinklers fully exposed to the hot gas flow generated by a fire. The first phase of the study was to determine the performance of RF\&C sprinklers in full scale fire tests. Fifteen full-scale fire tests were conducted. Using a thermal response model, it was possible to determine which of the RF\&C sprinklers had thermal sensitivities consistent with ISO sensitivity requirements for fully exposed sprinklers. Plunge tests were then conducted in the Factory Mutual Research Corporation plunge test tunnel with the sprinkler models used in the fire tests. A special plate to mount the recessed, flush and concealed sprinklers in the plunge test tunnel was fabricated with a closed plenum to contain the portion of the sprinklers that would typically be mounted above the ceiling in normal installation. A comparison of fire test results and plunge test results indicated that ceiling pressures generated by the fires needed to be simulated in the plunge test which was accomplished by evacuating the plenum of the mounting plate. Several combinations of plunge test temperatures and velocities, along with selected pressure differential accomplished by evacuating the plenum, were used in the plunge testing to simulate diverse ceiling flows generated by fires. It was observed that thermal sensitivity of RF\&C sprinklers could be evaluated, consistent with fire test results, if maximum allowed plunge test response times were less than or equal to those determined from ISO thermal sensitivity limits.
\end{abstract}

KEYWORDS: Sprinklers, thermal sensitivity, plunge test, RTI

\section{INTRODUCTION}

Recessed, flush and concealed (RF\&C) sprinklers have been approved by Factory Mutual Research Corporation (FMRC) ${ }^{(1,2)}$ and Underwriters Laboratories (UL) $)^{(3,4)}$ for many years. The following definitions for these categories of sprinklers have been established in the ISO 6182-1 standard for automatic sprinklers ${ }^{(5)}$ : 
Recessed (R) - A sprinkler of which all or part of the body, other than the shank thread, is mounted within a recess housing.

Flush (F) - A sprinkler of which all or part of the body, including the shank thread, is mounted above the lower plane of the ceiling, but part of, or all of, the heat responsive element is below the lower plane of the ceiling.

Concealed (C) A recessed sprinkler having a cover plate.

The acceptability of the thermal response characteristics of RF\&C sprinklers is determined by $\mathrm{FMRC}^{(1)}$ and $\mathrm{UL}^{(3)}$ through full-scale fire tests. In sharp contrast to these test methods, the ISO test method ${ }^{(5)}$ for standard and fast response sprinklers (pendent and sidewall) is based on a welldefined, scientifically verified ${ }^{(6-11)}$ response theory for heat responsive elements exposed directly to the hot gas flow ("fully exposed"). ISO has adopted the Response Time Index (RTI) and the Conduction Factor (C) as the parameters controlling the thermal sensitivity of fully exposed sprinklers. Three categories of sprinklers (standard, special and fast response) have been established based on RTI and C.

The ISO thermal sensitivity test methods evolved from a "plunge test" method developed by Heskestad and Smith ${ }^{(6,7)}$ at FMRC. In this method, the response time of the sprinkler was measured when the sprinkler was plunged into a heated wind tunnel with a constant temperature and velocity stream. Heskestad and Smith ${ }^{(6,7)}$ characterized the thermal sensitivity of a sprinkler in terms of a single parameter, the response time index (RTI). This parameter accounted for the thermal inertia of the sprinkler and the convective heat transfer coefficient from the gas to the sprinkler. More recently, Heskestad and $\mathrm{Bill}^{(8-10)}$ proposed an additional thermal sensitivity parameter, the conduction factor (C). In the new model, the time rate of rise of the sprinkler link temperature, dT/dt, depends on the two sprinkler parameters, RTI and C, the gas velocity, $\mathrm{U}_{\mathrm{g}}$, gas temperature, $T_{g}$, and the temperature of the pipe fitting, $T_{f}$. The model is given in Eq. (1), where $\mathrm{T}$ is the sprinkler link temperature:

$$
\frac{\mathrm{dT}}{\mathrm{dt}}=\frac{\mathrm{U}_{\mathrm{g}}^{1 / 2}}{\mathrm{RTI}}\left(\mathrm{T}_{\mathrm{g}}-\mathrm{T}\right)-\frac{\mathrm{C}}{\mathrm{RTI}}\left(\mathrm{T}-\mathrm{T}_{\mathrm{f}}\right)
$$

From a knowledge of a) the initial temperature of the sprinkler, and b) the gas velocity and temperature and the pipe fitting temperature as a function of time, the response relation Eq. (1) can be numerically integrated to determine the time at which the sprinkler link reaches the actuation temperature. The model [Eq. (1)] has been tested for steady and growing fires, for bulb and solder type sprinklers of varying thermal sensitivity and has been found to give excellent agreement with observed response times. ${ }^{(8-11)}$

RF\&C sprinklers cannot be assumed to be covered directly by the RTI concept because these sprinklers may not have heat responsive elements directly exposed to the hot gas flow. Concealed sprinkler heat responsive elements are not exposed to the hot gas flow until after the cover plate has fallen off. Even after this event, the element is not directly exposed. In the case of flush (F) sprinklers, the heat responsive element could be immersed in a ceiling boundary layer of reduced temperature and velocity.

The objective of the current study ${ }^{(12)}$ was to develop plunge test methods to evaluate the thermal sensitivity of RF\&C sprinklers. The first phase of the study was to establish the performance of 
RF\&C sprinklers (and, for comparison, standard and QR pendent and sidewall sprinklers) in full scale fire tests. From the fire tests, it was possible to determine which of the RF\&C sprinklers had thermal sensitivities consistent with ISO requirements for fully exposed sprinklers. The second phase of the study was to determine plunge test conditions for RF\&C sprinklers which would represent a wide range of fire conditions and give response results consistent with the fire tests.

\section{FULL SCALE FIRE TESTS}

\section{Test Facility and Instrumentation}

Full scale fire tests were conducted within an enclosure of the same size as that used in the study in which the conduction factor, $\mathrm{C}$, was introduced as a companion parameter to $\mathrm{RTI}^{(8-10)}$. The fire tests employed a test room within the "HUD" Building at FMRC. The room, as shown in Figure 1, measured $3.66 \mathrm{~m} \times 7.32 \mathrm{~m} \mathrm{x} 2.44 \mathrm{~m}$ high, and was made from wood studs and $1 / 2 \mathrm{in}$. gypsum board. There was only one opening to the room, an open door at one end. A fire source was placed near the opposite end, and ceiling sprinklers, together with associated instruments, were located at distances of $1.63 \mathrm{~m}$ and $4.55 \mathrm{~m}$ from the fire source. Each ceiling station, shown in Figure 1, incorporated two sprinklers, screwed into steel pipe extending $0.30 \mathrm{~m}$ above the ceiling. In a typical fire test the sprinklers located on the west side of the measurement stations were pendent, while an RF\&C sprinkler was installed on the east side. After a sprinkler had been installed for testing, the pipe to which it was mounted was filled with $100 \mathrm{ml}$ of water. The sprinkler sprays occurring at actuation were sufficiently weak that no significant fire suppression or gas cooling took place. A thermocouple monitored the water temperature within the waterway of each sprinkler.

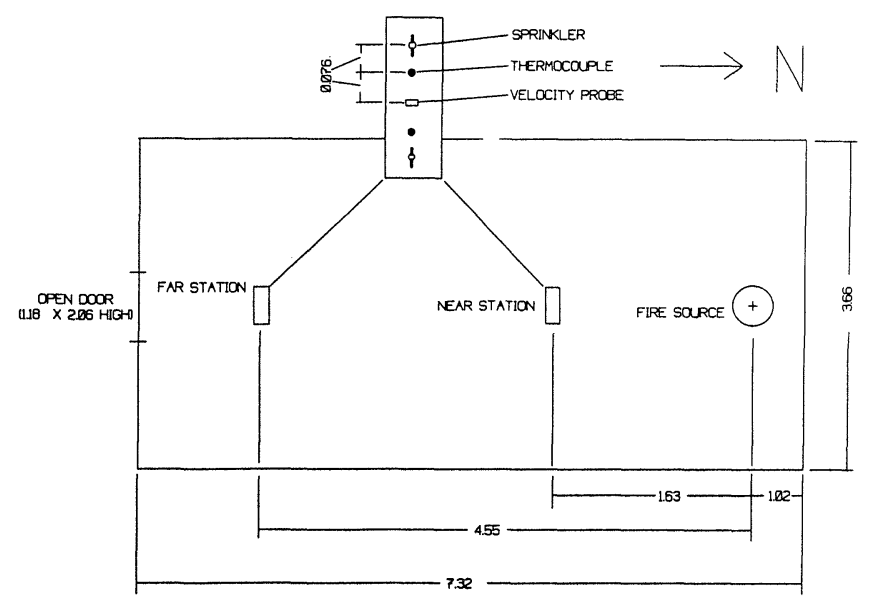

Figure 1. Fire room with two sprinklers and instrument stations. The fire source, a $0.46 \mathrm{~m}$ diameter heptane pool, was used as shown in all fire tests, except Test 7. All dimensions in $\mathrm{m}$. 
In order to record actuation times of the sprinklers, $1 / 8 \mathrm{in}$. diameter tubes, connected to one side of an electronic manometer, were positioned near the top of the $0.30 \mathrm{~m}$ long pipes above the sprinkler. When the sprinklers actuated, the water flow was sensed as a drop in pressure by the manometer, thus providing an event marker.

Along with the two sprinklers at each ceiling station, there were two thermocouples to measure gas temperature and one bi-directional flow probe (connected to an electronic manometer) to measure gas velocity, all at a sensing level of $76 \mathrm{~mm}$ beneath the ceiling. This position was approximately at the level of the heat responsive elements of the pendent sprinklers. It was observed in early fire tests that the gas temperatures measured by the two gas temperature thermocouples at each station were essentially equivalent. In addition to the instrumentation described above, a pressure port flush with the ceiling surface was placed in the center of the room. The port was connected to an electronic manometer with a $1 / 8 \mathrm{in}$. diameter line, referenced to the pressure above the ceiling.

\section{Description of Fire Tests and Results}

Sixteen fire tests were conducted in the facility described above. In all but one of these fire tests (Test 7), a $0.46 \mathrm{~m}$ diameter pool of heptane ( $3 \ell)$ floated on water $(2 \ell)$ was used as a fire source. From mass loss measurements made in a previous study ${ }^{(8)}$, it is estimated that the chemical heat release rate was $130 \mathrm{~kW}$. In Test 7, the pan diameter was increased to $0.6 \mathrm{~m}$. The position of the fire source is shown in Figure 1.

Twelve different sprinkler models were used in this study, obtained from five different sprinkler manufacturers, including two (fully exposed) pendent sprinklers. Two of the sprinklers were recessed sidewall sprinklers. Results from tests using sidewalls will not be discussed; however, the conclusions presented here are consistent with the sidewall results given in Reference 12, along with fuller details of the program. Table 1 lists the sprinkler characteristics except for the sidewalls $(\mathrm{E}$ and $\mathrm{F})$. In all of the fire tests, either a standard response pendent $(\mathrm{K})$ or a $\mathrm{QR}$ pendent $(\mathrm{L})$ was installed for reference.

Table 2 lists the sprinklers used in each fire test, except Tests 13 and 14, in which sidewall sprinklers were installed, and Test 15 with no sprinklers installed. Table 2 also lists the response time in each test, along with the calculated response time for the (exposed) pendent sprinklers based on Eq. 1, with the measured temperatures and velocities. All sprinklers were installed with their frame arms parallel to the north wall (standard orientation), except as noted. In Test 15, the south wall was removed to determine the effect of the changed opening on the magnitude of the static pressure measured at the room center. Because, somewhat unexpectedly, the pressure was significantly reduced, the fire test was repeated with sprinklers installed in this room configuration (Test 16).

Results for gas temperature, velocity, and sprinkler waterway temperature are similar to those observed in the study developing RTI and $\mathrm{C}^{(8,9)}$. The static room pressure differential at the ceiling relative to the space above the ceiling (a continuation of the space surrounding the door opening of the test compartment) is shown in Figure 2. The average pressure is about $0.007 \mathrm{~mm}$ $\mathrm{Hg}$ (higher below the ceiling than above). 
TABLE 1. Sprinkler Characteristics

\begin{tabular}{|c|c|c|c|c|}
\hline Model & Type & Link Type & $\begin{array}{c}(\mathrm{m} \cdot \mathrm{s})^{1 / 2} \text { of } \\
\text { Sprinkler Only }\end{array}$ & $\begin{array}{c}\text { Rating } \\
\left({ }^{\circ} \mathrm{C}\right)\end{array}$ \\
\hline A & $\begin{array}{l}\text { Recessed } \\
\text { Pendent }\end{array}$ & $3 \mathrm{~mm}$ bulb & 35 & 68.3 \\
\hline B & $\begin{array}{l}\text { Recessed } \\
\text { Pendent }\end{array}$ & $5 \mathrm{~mm}$ bulb & $135^{*}$ & 68.3 \\
\hline $\mathrm{C}$ & $\begin{array}{l}\text { Recessed } \\
\text { Pendent } \\
\text { (Vented) }\end{array}$ & Solder & $183^{*}$ & 73.9 \\
\hline D & $\begin{array}{l}\text { Recessed } \\
\text { Pendent }\end{array}$ & Solder & $183^{*}$ & 73.9 \\
\hline G & $\begin{array}{l}\text { Flush } \\
\text { Pendent }\end{array}$ & Solder & $34^{*}$ & 73.9 \\
\hline $\mathrm{H}$ & $\begin{array}{l}\text { Concealed } \\
\text { (vented) }\end{array}$ & Solder & 203 & 73.9 \\
\hline I & $\begin{array}{l}\text { Concealed } \\
\text { (vented) }\end{array}$ & Solder & 26 & 73.9 \\
\hline $\mathbf{J}$ & Concealed & Solder & $264^{*}$ & 73.9 \\
\hline $\mathrm{K}$ & Pendent & Solder & 203 & 73.9 \\
\hline $\mathrm{L}$ & Pendent & Solder & 26 & 73.9 \\
\hline
\end{tabular}

TABLE 2. Fire Test Results

\begin{tabular}{|c|c|c|c|c|c|}
\hline $\begin{array}{l}\text { Test } \\
\text { No. }\end{array}$ & Model & $\begin{array}{c}\text { Near } \\
\text { Response } \\
\text { (s) } \\
\end{array}$ & $\begin{array}{c}\text { Calculated } \\
\text { Response } \\
\text { (s) } \\
\end{array}$ & $\begin{array}{c}\text { Far } \\
\text { Response } \\
\text { (s) } \\
\end{array}$ & $\begin{array}{c}\text { Calculated } \\
\text { Response } \\
\text { (s) } \\
\end{array}$ \\
\hline \multirow[t]{2}{*}{1.} & $\mathrm{~K}(\mathrm{SP})^{1}$ & 178 & 185 & 323 & 307 \\
\hline & $\mathrm{L}(\mathrm{QR})^{2}$ & 82 & 64 & 93 & 86 \\
\hline \multirow[t]{2}{*}{2.} & $\mathrm{~K}(\mathrm{SP})$ & 219 & 244 & 417 & 395 \\
\hline & $\mathrm{I}(\mathrm{C})^{3}$ & No operation (wet link) & - & 297 & \\
\hline \multirow[t]{2}{*}{3.} & $\mathrm{~K}(\mathrm{SP})$ & 216 & 223 & 362 & 310 \\
\hline & $\mathrm{D}(\mathrm{R})^{4}$ & 282 & & No operation & \\
\hline \multirow[t]{2}{*}{4.} & $\mathrm{~K}(\mathrm{SP})$ & 227 & 227 & 369 & 337 \\
\hline & $\mathrm{H}(\mathrm{C})$ & 331 & & 500 & \\
\hline \multirow[t]{2}{*}{5.} & $\mathrm{~L}(\mathrm{QR})$ & 63 & 69 & 99 & 95 \\
\hline & $\mathrm{G}(\mathrm{F})^{5}$ & 57 & & 89 & \\
\hline \multirow[t]{2}{*}{6.} & $\mathrm{~K}(\mathrm{SP})$ & 238 & 225 & 410 & 439 \\
\hline & $C(R)$ & 233 & & 377 & \\
\hline \multirow[t]{2}{*}{$7 .^{\dagger}$} & $\mathrm{K}(\mathrm{SP})$ & 84 & 99 & 117 & 131 \\
\hline & $\mathrm{H}(\mathrm{C})$ & 122 & & 166 & \\
\hline \multirow[t]{2}{*}{8.} & $\mathrm{~L}(\mathrm{QR})$ & 78 & 77 & 113 & 102 \\
\hline & $A(R)$ & 77 & & 112 & \\
\hline \multirow[t]{2}{*}{9.} & $\mathrm{~L}(\mathrm{QR})$ & 59 & 64 & 90 & 85 \\
\hline & $A^{*}(R)$ & 94 & & 184 & \\
\hline \multirow[t]{2}{*}{10.} & $\mathrm{~K}(\mathrm{SP})$ & 152 & 161 & 285 & 251 \\
\hline & $\mathrm{J}(\mathrm{C})$ & 323 & & 506 & \\
\hline \multirow[t]{2}{*}{11.} & $\mathrm{~K}(\mathrm{SP})$ & 202 & 220 & 390 & 344 \\
\hline & $\mathrm{B}(\mathrm{R})$ & 193 & & 243 & \\
\hline \multirow[t]{2}{*}{12.} & $\mathrm{~K}$ (SP) & 170 & 222 & 285 & 251 \\
\hline & $B^{*}(\mathrm{R})$ & 192 & & 269 & \\
\hline \multirow[t]{2}{*}{$16 .^{t \dagger}$} & $\mathrm{K}(\mathrm{SP})$ & 217 & 232 & 413 & 350 \\
\hline & $C(R)$ & 244 & & 567 & \\
\hline
\end{tabular}

${ }^{1} \mathrm{SP}$ - standard response pendent; ${ }^{2} \mathrm{QR}$ - quick response pendent; ${ }^{3} \mathrm{C}$ - concealed sprinkler; ${ }^{4} \mathrm{R}$ - recessed sprinkler; ${ }^{5} \mathrm{~F}$ - flush sprinkler; ${ }^{*}$ Sprinkler mounted with frame arms parallel to the ceiling flow generated by the fire; ${ }^{\dagger} 0.61$ diameter pool fire; ${ }^{\dagger \dagger}$ South wall removed. 


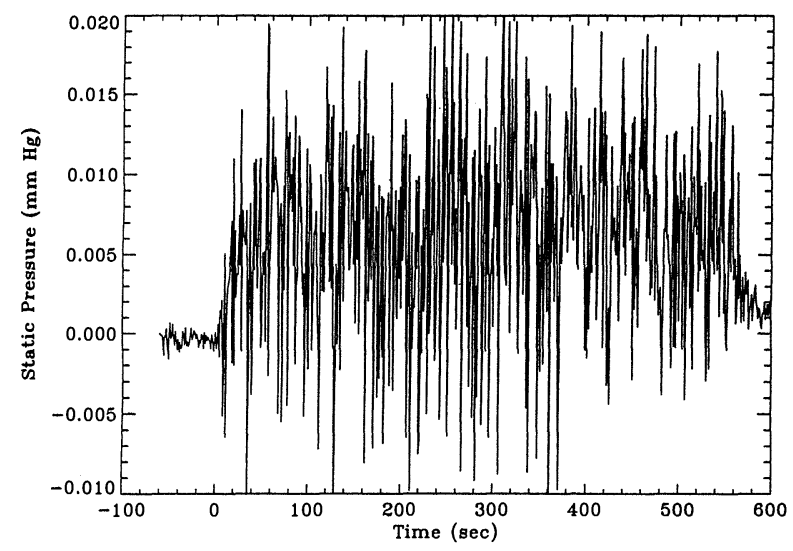

Figure 2. Static pressure at the ceiling in the room center, Test 1.

In Test 7 , the fire source was a $0.6 \mathrm{~m}$ heptane pool (5 l) floated on water ( $3 \ell)$. The resulting pressure differential was consistent with the increased (approximately double) heat release rate. The average pressure increased to $0.013 \mathrm{~mm} \mathrm{Hg}$. In test 16, with the south wall removed, the pressure differential was significantly decreased compared to Tests 1 through 14 , with the average pressure differential less than $0.002 \mathrm{~mm} \mathrm{Hg}$.

\section{Analysis of Fire Test Results}

In order to determine if the sensitivities of the RF\&C sprinklers are consistent with the allowed limits under ISO ${ }^{(5)}$, the response times for pendent sprinklers at the upper limits of RTI and C were calculated. Because the upper limit of RTI is a function of $\mathrm{C}$ for standard and fast response sprinklers, calculations have been made at two upper limits typical for the standard and fast response categories. For standard response, the two limits are: $\mathrm{RTI}=350(\mathrm{~m} \cdot \mathrm{s})^{1 / 2}, \mathrm{C}=1.0(\mathrm{~m} / \mathrm{s})^{1 / 2}$ and $\mathrm{RTI}=250(\mathrm{~m} \cdot \mathrm{s})^{1 / 2}, \mathrm{C}=2.0(\mathrm{~m} / \mathrm{s})^{1 / 2}$. For fast response sprinklers the limits are RTI $=50$ $(\mathrm{m} \cdot \mathrm{s})^{1 / 2}, \mathrm{C}=0.8(\mathrm{~m} / \mathrm{s})^{1 / 2}$ and RTI $=30(\mathrm{~m} \cdot \mathrm{s})^{1 / 2}, \mathrm{C}=1.0(\mathrm{~m} / \mathrm{s})^{1 / 2}$. These limits are established under ISO for a standard sprinkler orientation which for sprinklers with frame arms would be with the flow perpendicular to the plane of the frame arms.

In calculating the response times at the upper sensitivity limits, the measured gas velocities and temperature, and pipe fitting temperature were used in Eq. (1) as in the calculations for the pendent sprinklers. The pipe fitting temperature, $T_{f}$, was taken as the waterway temperature of the pendent sprinkler adjacent to the RF\&C sprinkler. The actuation temperature for calculation of maximum allowed times was taken as the temperature rating plus $3.5 \%$ (in units of ${ }^{\circ} \mathrm{F}$ ), the tolerance in the FMRC Approvals Standard ${ }^{(1)}$, nearly identical to ISO ${ }^{(5)}$.

In Table 3, the maximum allowed response times are listed for those fire tests in which the responses of the RF\&C sprinkler were greater than those of the installed pendent sprinklers. Note that in Tests 9 and 12, the recessed sprinklers were installed with the plane of the frame arms parallel to the ceiling flow generated by the fire. This is defined under ISO as the worst case 
condition. For Test 9, a calculation was made for an RTI of $125(\mathrm{~m} \cdot \mathrm{s})^{1 / 2}$ and a C of $2.0(\mathrm{~m} \cdot \mathrm{s})^{1 / 2}$, corresponding to the ISO upper RTI limit for fast response in the worst case orientation ${ }^{(5)}$. In Test 12 an RTI of $600(\mathrm{~m} \cdot \mathrm{s})^{1 / 2}$ and a C of $5.0(\mathrm{~m} \cdot \mathrm{s})^{1 / 2}$ were used in the calculations, corresponding to the RTI limit for standard response in worst case orientation ${ }^{0}$. Note that the C's selected were adjusted proportionately to $\mathrm{RTI}^{(10)}$.

TABLE 3. Comparison of Sprinkler Response with Maximum Allowed Response Under ISO

\begin{tabular}{|c|c|c|c|c|c|}
\hline \multirow[b]{2}{*}{$\begin{array}{l}\text { Test } \\
\text { No. }\end{array}$} & & & $\begin{array}{l}\text { Maximum } \\
\text { Resnonse Time(s) }\end{array}$ & $\begin{array}{c}\text { Maximum } \\
\text { Response Time(s) }\end{array}$ \\
\hline & & & $\begin{array}{l}\text { Response } \\
\text { Time(s) }\end{array}$ & $\begin{array}{l}\text { Response Time }(s) \\
(\mathrm{RTI}=350, \mathrm{C}=1)^{\dagger}\end{array}$ & $\begin{array}{l}\text { Response Time }(s \\
(\mathrm{RTI}=250, \mathrm{C}=2)^{\dagger}\end{array}$ \\
\hline \multirow[t]{2}{*}{$\overline{3}$} & $\mathrm{D}(\mathrm{R})^{1}$ & (near) & 282 & 303 & 358 \\
\hline & & (far) & No operation & 384 & No operation \\
\hline \multirow[t]{2}{*}{4} & $\mathrm{H}(\mathrm{C})^{2}$ & (near) & 331 & 300 & 315 \\
\hline & & (far) & 500 & 405 & No operation \\
\hline \multirow[t]{2}{*}{7} & $\mathrm{H}(\mathrm{C})$ & (near) & 122 & 138 & 127 \\
\hline & & (far) & 166 & 176 & 170 \\
\hline \multirow[t]{2}{*}{9} & $\mathrm{~A}^{*}(\mathrm{R})$ & (near) & 94 & $234^{* *}$ & -- \\
\hline & & (far) & 184 & $335^{* *}$ & -- \\
\hline \multirow[t]{2}{*}{10} & $\mathrm{~J}(\mathrm{C})$ & (near) & 323 & 252 & 260 \\
\hline & & (far) & 506 & 353 & 418 \\
\hline \multirow[t]{2}{*}{12} & $\mathrm{~B}^{*}(\mathrm{R})$ & (near) & 192 & No operation ${ }^{* * *}$ & -- \\
\hline & & (far) & 269 & No operation ${ }^{* * *}$ & -- \\
\hline \multirow[t]{2}{*}{16} & $\mathrm{C}(\mathrm{R})$ & (near) & 244 & 303 & 389 \\
\hline & & (far) & 567 & 421 & No operation \\
\hline
\end{tabular}

${ }^{1} \mathrm{R}$ - recessed sprinkler; ${ }^{2} \mathrm{C}$ - concealed sprinkler; ${ }^{3} \mathrm{RSW}$ - recessed sidewall on south wall.

"Sprinkler mounted with frame arms parallel to the ceiling flow generated by the fire.

${ }^{* *}$ Calculation based on RTI $=125(\mathrm{~m} \cdot \mathrm{s})^{1 / 2} ; \mathrm{C}=2.0(\mathrm{~m} / \mathrm{s})^{1 / 2}$.

${ }^{* * *}$ Calculation based on RTI $=600(\mathrm{~m} \cdot \mathrm{s})^{1 / 2} ; \mathrm{C}=5.0(\mathrm{~m} / \mathrm{s})^{1 / 2}$.

${ }^{\dagger} \mathrm{RTI}$ in $(\mathrm{m} \cdot \mathrm{s})^{1 / 2} ; \mathrm{C}$ in $(\mathrm{m} / \mathrm{s})^{1 / 2}$.

In Table 3, performance was deemed acceptable if sprinkler response was no greater than the maximum response at either of the upper sensitivity limits. In the case in which the calculation indicated that no operation would occur and the fire test indicated that no operation occurred, as at the far position in Test 3, the result was considered indeterminate. The results shown in Table 4 for sprinklers A (worst case orientation), B (worst case orientation), and C are acceptable, while those for sprinkler $\mathrm{J}$ are unacceptable. Note that sprinkler $\mathrm{A}$ and sprinkler $\mathrm{B}$ are acceptable as a fast response and a standard response sprinkler, respectively, because the results of both the standard orientation (Table 2) and worst case orientation (Table 3) meet the requirements. The results for sprinkler $\mathrm{D}$ are acceptable at the near position and indeterminate at the far position. The response of sprinkler $\mathrm{H}$ is acceptable in Test 7 , in which a $0.6 \mathrm{~m}$ diameter heptane pool fire was used. However, in Test 4, using the $0.46 \mathrm{~m}$ diameter heptane pool fire, the response time was unacceptable at the near position. 


\section{PLUNGE TESTING}

Modifications to the Standard Plunge Test

Because RF\&C sprinklers have at least some portion of their bodies above the ceiling, as a first step in adapting the plunge test, it was necessary to design and fabricate a new mounting plate for the RF\&C sprinklers to replace the standard mounting plate in the FMRC plunge test tunnel. The new mounting plate, as with the old, would form the top surface of the test section.

The final mounting plate design is shown in Figure 3. Notable features of the plate design include a plenum, a $1 \frac{1 / 4}{\mathrm{in}}$. (nominal $32 \mathrm{~mm}$ ) threaded coupling whose length within the plenum can be varied to accommodate the various geometries of RF\&C sprinklers, a $64 \mathrm{~mm}$ diameter sprinkler installation hole in a marinite plate housed inside a steel frame, a vacuum port in the plenum for generating a flow from the plunge tunnel test section though the plenum, and pressure ports to measure the differential pressure between the plenum and the plunge tunnel test section.

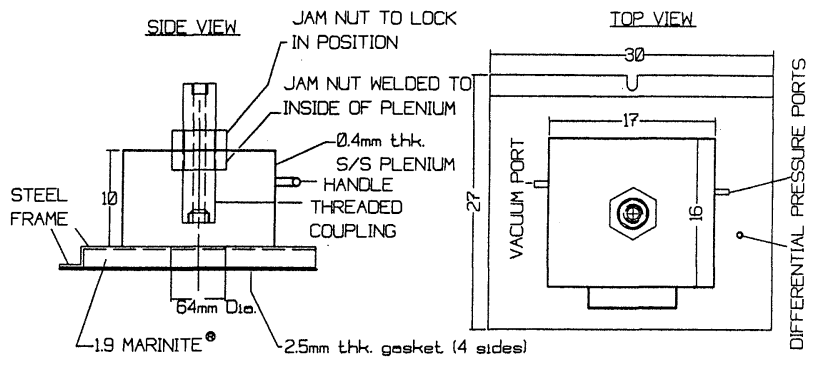

Figure 3. Schematic of mounting plate with plenum. "Threaded Coupling" connects an air hose fitting at the upper end to a sprinkler fitting at the lower end. Note: All dimensions in $\mathrm{cm}$ unless otherwise noted.

During the fire tests it was observed that a positive ceiling pressure was generated by the fires relative to the space above the ceiling. For comparison, the pressure of the tunnel test section was measured under a variety of test conditions. The tunnel pressures are significantly negative in contrast to the slightly positive pressures observed in the fire tests. In order to investigate the effect of the negative pressure, Model I (a concealed sprinkler with a fast response link) was introduced into the plunge tunnel using the new mounting plate without the vacuum connection in the plenum. Tunnel conditions of $128^{\circ} \mathrm{C}$ and $1 \mathrm{~m} / \mathrm{s}$ were selected from among conditions for which the tunnel has been calibrated to approximate fire Test 2 , in which the average gas velocity near the sprinkler was $0.7 \mathrm{~m} / \mathrm{s}$, and the average gas temperature after the initial temperature rise was $137^{\circ} \mathrm{C}$. Model I responded at the far location in $297 \mathrm{~s}$ (Table 2). In the plunge test, however, Model I failed to respond during a $1200 \mathrm{~s}$ period, after which the plunge test was aborted. The negative pressure for this condition was $0.045 \mathrm{~mm} \mathrm{Hg}$. From this result, it was judged that the residual negative pressure persisting in spite of the plenum may have adversely affected response.

Based upon the previous result and other sprinkler testing ${ }^{(12)}$, it was felt that any flow through the sprinkler housing which resulted from fire generated ceiling pressures needed to be simulated in 
the plunge test. This was found to be true even in the case of recessed sprinklers in which the only openings through the housing were small openings at the contact point between the outer recess cup and the inner plate holding the sprinkler. Simulation of flow through the sprinkler housing was accomplished with the aid of the vacuum port and differential pressure ports as in the final mounting plate design. Plunge tunnel conditions were set at $128^{\circ} \mathrm{C}$ and $1 \mathrm{~m} / \mathrm{s}$. Flow through the vacuum port was increased until the differential between the test section and the plenum was $0.007 \mathrm{~mm} \mathrm{Hg}$, similar to the ceiling pressure observed in Test 2. Given a tunnel gas temperature and velocity comparable to temperatures and velocities in fire Test 2 , the observed response of $332 \mathrm{~s}$ for Model I is reasonable. In two other tests at these conditions, Model I responded in 327 and $394 \mathrm{~s}$. To test the sensitivity of the results to pressure, two other plunge tests were conducted with the pressures at $0.010 \mathrm{~mm} \mathrm{Hg}$ and $0.015 \mathrm{~mm} \mathrm{Hg}$. The responses of Model I were $210 \mathrm{~s}$ and $211 \mathrm{~s}$, respectively. Observed pressures in the fire tests ranged between less than $0.002 \mathrm{~mm} \mathrm{Hg}$ (fire Test 16) and $0.013 \mathrm{~mm} \mathrm{Hg}$ (fire Test 7). We have selected a pressure differential of $0.007 \mathrm{~mm} \mathrm{Hg}$. as representative for a gas temperature of $128^{\circ} \mathrm{C}$.

Having developed a viable mounting plate, the next step in the program was to test the sprinklers used in the fire test program at various plunge test conditions. At each plunge test condition, the response of the RF\&C sprinkler was compared with the maximum allowed response time for either standard or fast response sprinklers using the maximum allowed RTI, C allowed under $\mathrm{ISO}^{(5)}$, and actuation temperature based on the actual temperature rating plus $3.5 \%$ (in units of ${ }^{\circ} \mathrm{F}$ ).

Nine plunge conditions were investigated. These are listed in Table 4. The pressure at the ceiling is expected, for a given room geometry, to be proportional to the temperature difference between the ceiling layer temperature and the ambient conditions above the ceiling and inversely proportional to the absolute temperature of the ceiling layer. Therefore, the differential pressures at higher gas temperatures than $128^{\circ} \mathrm{C}$ were scaled and the results are listed in Table 4 . The plunge test results and analysis are discussed in the following sections.

TABLE 4. Plunge Tunnel Conditions

\begin{tabular}{ccc}
$\begin{array}{c}\text { Gas } \\
\text { Temperature }\left({ }^{\circ} \mathrm{C}\right)\end{array}$ & $\begin{array}{c}\text { Gas } \\
\text { Velocity }(\mathrm{m} / \mathrm{s})\end{array}$ & $\begin{array}{c}\text { Gauge } \\
\text { Pressure }(\mathrm{mm} \mathrm{Hg})\end{array}$ \\
\cline { 2 - 3 } 128 & 1.0 & 0.007 \\
128 & 2.56 & 0.007 \\
128 & 3.48 & 0.007 \\
199 & 1.0 & 0.010 \\
197 & 2.56 & 0.010 \\
197 & 3.48 & 0.010 \\
301 & 1.0 & 0.013 \\
290 & 2.56 & 0.013 \\
289 & 3.48 & 0.013
\end{tabular}

Plunge Testing and Analysis of Results

Model sprinklers A through J were tested using the new mounting plate under the flow conditions shown in Table 4. Each model sprinkler was typically tested three times at each tunnel condition and sprinkler evaluations were based upon the average response time. Sprinklers with solder links were tested with the plane of the frame arms perpendicular to the flow with the link in the downstream position. In the case of sprinklers with bulb actuation links, some conditions were 
tested with the plane of the frame arms perpendicular to the flow (ISO ${ }^{(5)}$ standard orientation), parallel to the flow (ISO ${ }^{(5)}$ worst case orientation), and with an angular offset from the worst case orientation of $15^{\circ}$ or $25^{\circ}$, as required by $\mathrm{ISO}^{(5)}$ for plunge testing of standard or fast response sprinklers, respectively.

In order for a given sprinkler model to be acceptable, the proposition was considered that the plunge test response times for conditions in Table 4, be less than or equal to the response times that would be calculated using the thermal response model defined by Eq. (1) and the upper limits of RTI and C allowed under ISO. For plunge test conditions the solution of Eq. (1) is:

$$
\mathrm{t}_{\mathrm{r}}=\frac{-\mathrm{RTI} \ell \mathrm{n}\left(1-\frac{\left(\mathrm{T}_{\mathrm{a}}-\mathrm{T}_{\mathrm{f}}\right)}{\left(\mathrm{T}_{\mathrm{g}}-\mathrm{T}_{\mathrm{f}}\right)}\left(1+\mathrm{C} / \mathrm{U}_{\mathrm{g}}^{1 / 2}\right)\right)}{\mathrm{U}_{\mathrm{g}}^{1 / 2}+\mathrm{C}}
$$

where variables are defined as in Eq. (1), and the actuation temperature is denoted as $\mathrm{T}_{\mathrm{a}}$. For standard response, times were calculated for RTI $=350(\mathrm{~m} \cdot \mathrm{s})^{1 / 2}, \mathrm{C}=1.0(\mathrm{~m} / \mathrm{s})^{1 / 2}$ and for RTI $=$ $250(\mathrm{~m} \cdot \mathrm{s})^{1 / 2}, \mathrm{C}=2.0(\mathrm{~m} / \mathrm{s})^{1 / 2}$. Fast response calculations were made for RTI $=50(\mathrm{~m} \cdot \mathrm{s})^{1 / 2}, \mathrm{C}=0.8$ $(\mathrm{m} / \mathrm{s})^{1 / 2}$ and $\left.\mathrm{RTI}=30(\mathrm{~m} \cdot \mathrm{s})^{1 / 2}, \mathrm{C}=1.0(\mathrm{~m} / \mathrm{s})^{1 / 2}\right)$. In addition, response times were calculated for worst case orientation, including RTI $=600(\mathrm{~m} \cdot \mathrm{s})^{1 / 2}, \mathrm{C}=5.0(\mathrm{~m} / \mathrm{s})^{1 / 2}$ for standard response and $\mathrm{RTI}=125(\mathrm{~m} \cdot \mathrm{s})^{1 / 2}, \mathrm{C}=2.0(\mathrm{~m} / \mathrm{s})^{1 / 2}$ for fast response. Actuation temperatures were taken as $77^{\circ}$ $\mathrm{C}$ and $71^{\circ} \mathrm{C}$, corresponding to the upper tolerance for $74^{\circ} \mathrm{C}$ and $68^{\circ} \mathrm{C}$ temperature rated sprinklers used in the program. Note that for some plunge test conditions, no solution to Eq. (2) exists $\left(t_{r}=\infty\right)$, indicating that sprinkler actuation would not occur for these conditions.

The results of the plunge tests were consistent with the conclusions of the fire tests if performance is deemed acceptable when the sprinkler response is less than the greatest allowed response time for all the selected plunge test conditions (Table 4). This was true for sprinklers tested in either the standard orientation on in the worst case orientation (sprinklers A and B in fire Tests 9 and 12 , respectively). Sprinklers B, C, D, and I qualified as standard response sprinklers. Sprinkler A qualified as a fast response sprinkler. As also concluded from the fire tests, sprinklers $\mathrm{H}$ and $\mathbf{J}$ were unacceptable. All of the plunge test conditions were not completed for sprinkler $\mathbf{G}$ and therefore no final evaluation was made. Some typical plunge test results are shown in Table 5.

TABLE 5. Some Plunge Test Results at Gas Temperatures of $197-199^{\circ} \mathrm{C}$ for Sprinklers in Their Standard $\mathrm{ISO}^{(5)}$ Orientation

\begin{tabular}{ccccc} 
Model & $\begin{array}{c}\text { Plunge Test Gas } \\
\text { Velocity }(\mathrm{m} / \mathrm{s})\end{array}$ & $\begin{array}{c}\text { Observed } \\
\text { Response }(\mathrm{s})\end{array}$ & $\begin{array}{c}\text { Maximum Allowed } \\
\text { Response }(\mathrm{s})\end{array}$ & $\begin{array}{c}\text { Apparent* } \\
\text { RTI }(\mathrm{m} \cdot \mathbf{s})^{1 / 2}\end{array}$ \\
\cline { 2 - 3 } & 1.0 & 12 & 20 & 38 \\
& 2.6 & 8 & 12 & 40 \\
$\mathrm{C}$ & 3.5 & 8 & 10 & 47 \\
& 1.0 & 76 & 259 & 212 \\
& 2.6 & 50 & 100 & 246 \\
$\mathrm{H}$ & 3.5 & 48 & 83 & 612 \\
& 1.0 & 220 & 259 & 699 \\
& 2.6 & 159 & 99 & 676
\end{tabular}

*Calculated assuming $\mathrm{C}=0$. 
Although the convective flows past RF\&C sprinklers are more complex than for standard sprinklers and the characteristic velocity, $\mathrm{U}_{\mathrm{g}}$, associated with the convective heat transport is unknown, it is an open question whether Eq. (2) and the RTI concept apply to RF\&C sprinklers. We calculated an "apparent" RTI for all plunge test results using Eq. (2), assuming C =0. Some of the results are indicated in Table 5. The RTI's can be seen to be relatively constant.

All nine plunge test conditions could in principle be used to evaluate acceptable response. However, those plunge test conditions which give no operation at the upper sensitivity limits provide no information and are not required for evaluation.

In the present study, only ordinary-temperature-rated sprinklers were investigated. Higher temperature-rated-sprinklers may be evaluated, in principle, using nine plunge test conditions with revised gas temperatures appropriate to the temperature rating with the lowest value as indicated in Table 7 of Reference 6.

\section{CONCLUSIONS}

1. Plunge tests have shown that flows through recessed and concealed sprinklers, generated by pressure differentials associated with hot ceiling layers, are important for the actuation of such sprinklers.

2. Plunge testing indicates that adverse pressure differentials can cause recessed and concealed sprinklers to fail to actuate.

3. Plunge testing can be used to evaluate sensitivity of recessed, flush and concealed sprinklers by using a modified mounting plate with a plenum, simulating fire induced pressures at the ceiling, and requiring the response times for several combinations of plunge test temperature and velocity to be no greater than values determined from ISO $^{(5)}$ thermal sensitivity limits for "exposed" sprinklers.

\section{ACKNOWLEDGMENTS}

This study was conducted under the FMRC Approvals Support Program. We wish to acknowledge the technical advice of Mr. Roger Allard and Mr. Richard Ferron. We thank Mr. William Brown for his technical assistance in the fabrication of the mounting plate. Mr. Richard Ferron and Mr. Edward Hill conducted the plunge tests.

\section{REFERENCES}

1. "Draft Approval Standard, Automatic Sprinklers for Fire Protection Service," Class Nos. 2001, 2002, 2005, 2006, 2012, 2013, 2015, 2016, 2017, 2043, 2050, 2060, Factory Mutual Research Corporation, Norwood, MA, December 1983.

2. "Approval Guide 1996, A Guide to Equipment, Material, and Services Approved by Factory Mutual Research Corporation," Factory Mutual Research Corporation, Norwood, MA, 1996. 
3. "Automatic Sprinklers for Fire Protection Service," UL 199, Underwriters Laboratories Inc., Northbrook, IL, February 16, 1994.

4. "Fire Protection Equipment, 1996 Directory," Underwriters Laboratories Inc., Northbrook, IL, 1996.

5. "ISO 6182-1, Fire Protection - Automatic Sprinkler Systems, Part 1, Requirements and Methods of Tests for Sprinklers," International Standards Organization, Second Edition, Geneva, Switzerland, 1994.

6. Heskestad, G. and Smith, H.F., "Investigation of a New Sprinkler Sensitivity Approval Test: The Plunge Test," FMRC 22485, Factory Mutual Research Corporation, Norwood, MA, December 1976.

7. Heskestad, G. and Smith, H.F., "Plunge Test for Determining Sprinkler Sensitivity," Technical Report J.I. 3A1E2.RR, Factory Mutual Research Corporation, Norwood, MA, December 1980.

8. Heskestad, G. and Bill, R.G., Jr., "Conduction Heat-Loss Effects on Thermal Response of Automatic Sprinklers" Technical Report J.I. 0N0J5.RU/0N1J6.RU, Factory Mutual Research Corporation, Norwood, MA, September 1987.

9. Heskestad, G. and Bill, R.G., Jr., "Quantification of Thermal Responsiveness of Automatic Sprinklers Including Conduction Effects" Fire Safety J., 14, 113-125, 1988.

10. Heskestad, G. and Bill, R.G., Jr., "Modeling of Thermal Responsiveness of Automatic Sprinklers," 2nd International Symposium on Fire Safety Science, IAFSS, Tokyo, Japan, Hemisphere Publishing Corp., New York, 1989.

11. Bill, R.G., Jr., "Thermal Sensitivity Limits of Residential Sprinklers," Fire Safety J., 21, 131-152, 1993.

12. Bill, R.G., Jr. and Heskestad, G., "Plunge Test Procedures for Recessed, Flush, and Concealed Sprinklers," Technical Report J.I. OY0J1.RA, Factory Mutual Research Corporation, Norwood, MA, February 1995. 